\title{
Evidence that phylogenetically novel non-indigenous plants experience less herbivory
}

Post-print/Accepted manuscript

Steven Burton Hill

Peter M. Kotanen

Hill, S.B. \& Kotanen, P.M. Oecologia (2009) 161: 581. doi:10.1007/s00442-009-1403-0

The final publication is available at Springer via http://dx.doi.org/10.1007/s00442-009-1403-0

\section{HOW TO CITE TSPACE ITEMS}

Always cite the published version, so the author(s) will receive recognition through services that track citation counts, e.g. Scopus. If you need to cite the page number of the TSpace version (original manuscript or accepted manuscript) because you cannot access the published version, then cite the TSpace version in addition to the published version using the permanent URI (handle) found on the record page. 


\section{Evidence that phylogenetically novel non-indigenous plants experience less}

\section{2 herbivory}

3

4 Steven B. Hill ${ }^{1^{*}}$ and Peter M. Kotanen ${ }^{2}$

5 Department of Ecology and Evolutionary Biology

6 University of Toronto at Mississauga

73359 Mississauga Road N

8 Mississauga $\mathrm{ON}$

9 L5L 1 C6

10 Canada

11 tel: 905-828-5365; fax: 905-828-3792

12 1e-mail: sb.hill@utoronto.ca

13 2e-mail: peter.kotanen@utoronto.ca

14

$15 *$ Author for correspondence

16

17

18 
Abstract

The degree to which biotic interactions influence invasion by non-indigenous species may be partly explained by the evolutionary relationship of these invaders with natives. Darwin's

Naturalization Hypothesis controversially proposes that non-native plants are more likely to invade if they lack close relatives in their new range. A possible mechanism for this pattern is that exotics that are more closely related to natives are more likely to share their herbivores, and thus will suffer more damage than phylogenetically isolated species.

We tested this prediction using exotic plants in Ontario, Canada. We measured herbivore damage to 32 species of exotic plants in a common garden experiment, and 52 in natural populations. We estimated their phylogenetic distances from locally-occurring natives in three ways: as mean distance (age) to all native plants, mean distance to native members of the same family, and distance to the closest native species.

In the common garden, the proportion of leaves damaged and the average proportion of leaf area damaged declined with mean phylogenetic distance to native family relatives by late summer. Distance to native confamilials was a better predictor of damage than distance to the closest native species, while mean distance to the entire native plant community failed to predict damage. No significant patterns were detected for plants in natural populations, likely because uncontrolled site-tosite variation concealed these phylogenetic trends. that are more phylogenetically isolated from native confamilials should be more invasive; conversely, native communities should be more resistant to invasion if they harbour close familial relatives of potential invaders. However, the large scatter in this relationship suggests that these often are likely to be weak effects; as a result, these effects often may be difficult to detect in uncontrolled surveys of natural populations. 
44 Key words: Biological invasions, biotic resistance, community phylogenetics, enemy release, natural 45 enemies. 
Introduction

Invasions by non-indigenous (exotic) plants now have affected most ecosystems around the world (Mack et al. 2000; Pimentel et al. 2000; Crall et al. 2006). Despite their pervasiveness, predicting the invasion potential of exotic species remains difficult. Some of this difficulty may stem from the complexity of interactions between potential invaders and their natural enemies and competitors in the invaded region. Numerous theories have been proposed to describe these biotic interactions (Mitchell et al. 2006), of which one of the most prominent is the Enemy Release Hypothesis (ERH) (Keane and Crawley 2002; Torchin and Mitchell 2004). The ERH proposes that exotic species leave behind natural enemies in their native range, resulting in an advantage relative to native competitors (Keane and Crawley 2002; Torchin and Mitchell 2004). Despite its apparent promise, tests of the ERH have found variable results (Colautti et al. 2004; Liu and Stiling 2006): some invaders apparently do benefit from reduced damage, but many do not (e.g., Agrawal et al. 2003; Parker \& Hay 2005; Liu et al. 2007).

One reason that enemy release often fails is that exotic plants rapidly can accumulate enemies in invaded regions, replacing those lost in the invasion process (e.g., Parker and Hay 2005; Parker et al. 2006; Hawkes 2007). This accumulation may be more likely for exotics with close native relatives in the invaded area, since shifts of enemies should be more likely among closely related hosts (Strong et al. 1984; Lewinsohn et al. 2005). Numerous studies provide evidence that phytophagous insects are more likely to be shared as the phylogenetic distance between hosts declines (e.g., Novotny et al. 2002; Novotny and Basset 2005; Odegaard et al. 2005). For instance, in an extensive survey of host use by herbivorous tropical insects, Weiblen et al. (2006) found that 25\% of the variance in herbivore community similarity was explained by the phylogenetic proximity of their hosts. Such trends extend to other taxa of natural enemies as well: by experimentally transferring fungal pathogens among plants, Gilbert \& Webb (2007) showed the likelihood that disease symptoms developed decreased with the phylogenetic separation of the species used as the source and target of the inoculum. If natural enemies 
72

can readily spread from natives to related exotics, then non-native plants with close relatives in the native flora might experience reduced enemy release and ultimately diminished invasiveness.

The idea that phylogeny might affect invasion success is not new. Darwin (1859) predicted that exotics related to native species would be better invaders, since they would be expected to thrive in environments similar to those that these natives evidently found suitable. He was surprised to find that in fact they were less frequently successful, a pattern which has been termed Darwin's Naturalization Hypothesis (Daehler 2001). Empirical support for Darwin's Naturalization Hypothesis varies: Daehler (2001) and Duncan and Williams (2002) rejected the idea, but other studies have had positive results (e.g., Rejmánek 1996; Diez et al. 2008). One potential problem is that all of these studies used a taxonomic, rather than a phylogenetic approach. In one of the few studies which has used a phylogenetic analysis, Strauss et al. (2006) found that invasive exotic grasses in California are more likely to belong to lineages that have lower native species diversity, though they did not identify the mechanism responsible for this pattern. One possibility is competition: if closely related species compete more strongly, as Darwin (1859) argued, then exotics might be competitively excluded from areas where native congeners occur. Whether the assumptions underlying this explanation are realistic is unclear, however; for example, Cahill et al. (2008) found only weak evidence that closer relatives compete more strongly. An attractive alternative is provided by shared natural enemies: if enemy release is less effective for exotics with close relatives in the invaded community, as suggested above, then the result could be the patterns observed by Strauss et al. (2006) and Darwin (1859).

The only studies to date which have tested whether herbivory is greater for exotics with native relatives have produced both positive (Dawson et al. 2009) and negative (Cappuccino and Carpenter 2005) results; none has attempted a phylogenetic approach. In our study, we used a common garden experiment and surveys of natural populations to determine whether the herbivore damage experienced by exotic plants is correlated with their phylogenetic relationship to native species. We predicted that the foliar damage experienced by an exotic species (1) decreases with phylogenetic distance to the 
closest locally-occurring native species, (2) decreases with phylogenetic distance to native members of

98 the same family, and (3) decreases with phylogenetic distance to the entire native community. We

99 provide evidence that damage declines with increasing distance to native confamilials, and possibly with distance to the closest native species. These results suggest that herbivory may contribute to the patterns suggested by Darwin's Naturalization Hypothesis. As well, they suggest both a reason for variation in the applicability of the Enemy Release Hypothesis, and potential avenues for improving the 103 precision and predictiveness of this hypothesis.

\section{Materials and Methods}

106 Study site

This study was conducted at the University of Toronto's Koffler Scientific Reserve (KSR) at

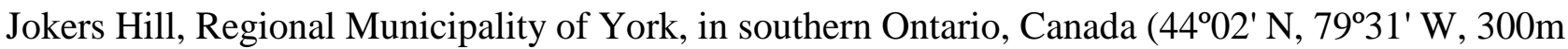
ASL). This 350-ha site lies within the Oak Ridges Moraine, and is dominated by prominent hills with a thin organic layer over deep glacial sands. Vegetation is a mixture of old fields supporting a diverse range of native and exotic plants, hardwood (maple-beech-hemlock) forest, and conifer plantations.

112 Further information on this site may be found at http://www.ksr.utoronto.ca/jh.html/.

\section{Common garden experiment}

114 We conducted a common garden experiment using 32 exotic old-field species (Table 1) selected on the basis of their presence in the KSR flora, taxonomic diversity, and availability. Twenty-six of our experimental species were germinated in a greenhouse from seed collected in southern Ontario and grown for 6-8 weeks before transplantation into the field. These were supplemented with six additional species transplanted from local populations; t-tests on damage measurements between transplanted and non-transplanted species confirm that there was no difference between seed-grown and transplanted individuals ( $p=0.244$ and $p=0.205$, respectively). In June 2005, six plants of each species were randomly assigned to one of eight 50m x 8m plowed and disked common gardens located in different 
122 old field sites. Landscape fabric was laid over the plowed plots to reduce the density of competitors.

123 Dominant species adjacent to the plots included Bromus inermis Leyss., Chrysanthemum

124 leucanthemum L., Cirsium arvense (L.) Scop., Daucus carota L., Poa compressa L., and Solidago

125 canadensis L.

126 We measured herbivore damage to all plants twice during the 2005 growing season: once shortly

127 after transplantation in late June (early summer), and once in late August (late summer). We made no

128 effort to distinguish damage by particular species; this is appropriate since we wished to integrate net

129 damage to plants by the entire herbivore community. On each date, the proportion of leaves damaged

130 per plant was measured; if the total number of leaves was greater than 50 , this proportion was

131 estimated from a haphazard sample of 50 leaves. We also examined photographs of 1 to 5 haphazardly

132 chosen damaged leaves per plant to visually estimate the fraction of leaf area consumed (to the nearest

$1335 \%$ ). Accuracy of this method was assessed by comparing visual estimates with digital estimates of the

134 minimum area removed for a subset of 380 leaves $\left(r^{2}=0.84\right.$ for comparison of visual and digital

135 assessment). The proportion of leaves damaged and the proportion of area removed per damaged leaf

136 were combined to produce an index of the fraction of leaf area damaged per plant:

137 proportion of leaf area damaged $=$ proportion of leaves damaged $\times$ average proportion of area removed from damaged leaves.

139 Natural population surveys

140 We also conducted a survey of damage in natural populations of 52 exotic species at KSR (Table

141 1); between 2 and 30 plants from between 2 and 6 populations per species (as available) were sampled

142 during July and August 2005. Since our aim was to be as inclusive as possible, we measured damage to

143 species that are found in forest understory and riparian/wetland habitats, as well as in old fields.

144 Damage was measured using the same approach as in the common gardens, except that the leaf area 145 damaged was measured in the field instead of using photographs in the lab.

146 Estimating relationship 
148 decades (Hillis 1987); however, many comparative ecological studies still rely on traditional taxonomic 149 ranks as a surrogate for phylogenetic relationship (e.g., Agrawal et al. 2005; Diez et al. 2008). Here, 150 we used phylogenetic approaches to quantify each exotic species' relationship to locally occurring 151 natives (i.e., those recorded on the KSR checklist: http://www.ksr.utoronto.ca/: site accessed 8 October 152 2008). We chose this small geographic scale because biotic interactions such as competition and

153 herbivory are expected to be important only if the potentially interacting species locally co-occur (Diez 154 et al. 2008; Proches et al. 2008).

For our phylogenetic analyses, we created a composite phylogeny of all the plants present at KSR using the "Maximally Resolved Seed Plant" tree in the program PHYLOMATIC (Webb and Donoghue 2005: http://www.phylodiversity.net/phylomatic/). The resulting tree had many polytomies at the family level, but we resolved within-family relationships for our study species using the following published phylogenies: Apiaceae (Downie et al. 2000), Asteraceae (Funk et al. 2005), Boraginaceae (Långström and Chase 2002), Brassicaceae (Bailey et al. 2006), Caryophyllaceae (Oxelman et al. 1996; Smissen et al. 2002), Lamiaceae (Wagstaff et al. 1998; Paton et al. 2004), Orchidaceae (Freudenstein et al. 2004), Plantaginaceae (Ronsted et al. 2002), Ranunculaceae (Ro et al. 1997), Rosaceae (Smedmark and Erickson 2002; Potter et al. 2007), Rubiaceae (Natali et al. 1995), Scrophulariaceae (Olmstead et al. 2001). Branch lengths for the resulting tree were adjusted using the "bladj" function in PHYLOCOM (Webb and Donoghue 2005: http://www.phylodiversity.net/phylocom/), which calibrates unknown node ages by linear interpolation of ages from Wikstrom et al. (2001). Three measures of the phylogenetic relatedness of our exotics to the native species at KSR were then extracted from this tree: 1) mean evolutionary distance (in years of divergence between tips of the tree) of each exotic to all native plants occurring at KSR; 2) the mean distance from each exotic to all 170 locally co-occurring native family members (in the absence of family members, the distance of each exotic to the next nearest lineage were used); and 3) the distance of each exotic to the closest native 
172 species. Distance to all native plants provides a description of each exotic's isolation from the entire

173 native community (e.g., Strauss et al. 2006); distance to native confamilials recognizes that enemies are

174 often shared at the family level (Novotny and Basset 2005; Odegaard et al. 2005; Weiblen et al. 2006).

175 Regressing damage against each of these distance measures provides a test of the hypothesis that

176 damage declines with this measure of phylogenetic isolation, consistent with the patterns predicted

177 from Darwin's Naturalization Hypothesis.

178 Statistical analyses

179 Since we primarily were interested in interspecific variation in herbivory, we treated species

means as data points. These were calculated by computing plot means (common garden experiment) or population means (field survey) for damage to individuals of each species, then averaging those values.

This approach also allowed us to avoid pseudoreplication and to simplify our comparative analyses, which are difficult to apply to spatially replicated datasets. The proportion of leaves damaged and the average leaf area damaged were analyzed separately, since they are algebraically nonindependent.

Damage measurements were probit transformed to linearize proportional measurements; arcsin transformation produced very similar results. All phylogenetic distance measurements were transformed using their natural logarithm to better meet statistical assumptions of normality and homoscedasticity. Statistical analyses were conducted using the programs R (R Development Core Team 2006) and JMP v5.0. (SAS Institute Inc. 2002). Results are reported as mean \pm standard error. Linear regression was used to test whether damage declined with phylogenetic distance from native relatives, for both the common garden experiment and the field survey. In the case of the common garden data, June and August samples were analyzed independently, since they effectively tested different hypotheses: June samples acted as a control to test for unwanted and unexpected initial

194 differences among newly-transplanted plants, while August samples provided useful data since they recorded cumulative damage over the summer. Since the plants sampled in the field survey had not 
competing measures of phylogenetic distance (distance to nearest native species, native confamilials,

198 and native community) by using Akaike's Information Criteria (Burnham and Anderson 2002): for

199 cases where at least one competing model was statistically significant, the combination of high Akaike

200 weights and high strength of fit $\left(\mathrm{r}^{2}\right)$ identifies the simplest and most powerful model.

201 To determine whether the inclusion of multiple species from some families biased any significant 202 results, we ran regressions of damage vs. distance using all possible combinations of species, subject to 203 the constraint that only one species was used to represent each family. This resulted in 432 and 84480 204 models for the common garden experiment and the survey respectively. The value of the regression 205 slope when all species were included compared to the distribution of slopes from models lacking 206 within-family replication allowed us to determine if our results were biased by family-level 207 phylogenetic nonindependence.

\section{Results}

At the June sampling of the common garden there were no significant effects of phylogenetic distance on damage (Table 2), indicating no unwanted initial differences. By the August sampling,

212 however, the proportion of leaves damaged (mean \pm SE: $0.44 \pm 0.05$ ) and the leaf area damaged (mean $213 \pm$ SE: $0.05 \pm 0.003$ ) both declined significantly with mean phylogenetic distance from native 214 confamilials, respectively explaining $12 \%$ and $18 \%$ of variation (Fig 1, Table 2). As well, there was a 215 marginally significant negative relationship between leaf area damaged and distance to the closest 216 native species $\left(\mathrm{p}=0.083, \mathrm{r}^{2}=7 \%\right.$; Table 2$)$. Models including only one species per family were 217 consistent with these results: 95\% quantiles for slopes of these reduced models did not include 0, but 218 did include the slopes estimated in our significant regressions; this indicates our significant results were 219 not an artefact of including multiple species per family. In contrast, there was no statistical relationship 220 between either damage measurement and mean distance to all locally-occurring natives. Mean distance 
221

to native family members was a much stronger predictor of damage than the other distance measures, as indicated by lower AIC and higher Akiake weights (w) and $\mathrm{r}^{2}$ values (Table 2).

In contrast with the common garden results, damage to exotics in natural populations was not significantly related to any of the phylogenetic distance measures (Table 2; Fig. 2). In all cases, adjusted $r^{2}$ values were very low or slightly negative (Table 2), indicating that essentially none of the variation in damage could be explained by phylogenetic distance to native relatives.

\section{Discussion}

Does damage decline with phylogenetic distance between natives and exotics?

We predicted that herbivore damage to exotics would decline with phylogenetic distance from native relatives. Few tests of related hypotheses have been performed. Working in Tanzania, Dawson et al. (2009) found herbivory in introduced plants increased with both the presence of native congeners and the diversity of native confamilials, though this was apparently unrelated to invasiveness. In contrast, also working in Ontario, Cappuccino and Carpenter (2005) found that herbivore damage to exotic plants was unrelated to the number of native congeners or confamilial native genera. Neither of these studies employed a phylogenetic approach, but using methods based on phylogenetic distance rather than the number of congeneric or confamilial native species, we found that both the proportion of leaves damaged and the average proportion of leaf area damaged declined with phylogenetic distance from confamilials (Fig. 1). As well, the leaf area damaged showed a nearly significant decline with phylogenetic distance from the nearest native species (Fig. 1). Remarkably, we were able to detect these patterns despite both phylogenetic uncertainty and the high level of noise resulting from interspecific variation in damage; nonetheless, the strength of these relationships was low $\left(r^{2}<0.2\right)$, suggesting the effects of native relatives often may be small relative to other factors affecting both herbivore damage and invasiveness. 
In contrast with our common garden results, we found no significant phylogenetic trends in

damage to wild populations (Fig. 2). The most plausible explanation is that uncontrolled variation in damage among natural populations was greater than any phylogenetic trend, and therefore masked the effects of phylogenetic distance. This does not necessarily mean phylogenetic influences are unimportant in natural populations; only that they operate in addition to other sources of background variation. Herbivore communities are highly spatially variable and often differ among habitats (e.g., DeWalt et al. 2004). We sampled scores of natural populations in a wide range of habitats; site-to-site variation in background levels of herbivore damage thus likely varied considerably. In contrast, experimental plants in our common gardens all shared the same environment, minimizing unwanted site effects. This reduction of environmental noise is one of the principal advantages of common gardens, since it can allow the detection of subtle trends that may be difficult to demonstrate in field surveys. Interestingly, the only other study we are aware of that shows an effect of phylogenetic isolation on herbivory (Dawson et al. 2009) was conducted in a botanical garden: effectively a common-garden approach.

Generally speaking, closer relatives share more of the herbivore community (Novotny et al. 2002; Novotny and Basset 2005; Odegaard et al. 2005; Weiblen et al. 2006); therefore, we expected that distance to the nearest relative (often a congeneric) would be the strongest predictor of damage. The stronger predictive value of family relatedness than distance to the nearest native relative was unexpected. There are several possible explanations for our result. First, many characteristics of plants that are important to herbivores are shared at the family level (chemistry, morphology, etc.); perhaps the single closest relative is less important than the suite of confamilials sharing such characteristics. There is some evidence that family-level characters can be more important in determining herbivore communities than variation among species within a family; for example, Cappuccino and Carpenter (2005) provide evidence that, although invasive exotic plants tend to be chemically more unusual than non-invasive exotic species, phytochemical uniqueness may only be weakly correlated with phylogeny 
below the family level. Second, deeper phylogenetic nodes where ecological or functional similarities

are conserved may represent greater species diversity than a single nearest neighbour; thus, relatives at the family level may harbour a greater diversity of insects potentially able to colonize a new invader than does a single close relative. While Cappuccino and Carpenter (2005) found damage to exotics to be unrelated to the diversity of native relatives, Dawson et al. (2009) did find that herbivore damage increased with the diversity of native confamilials, consistent with this prediction. Finally, the stronger effect of family relationship may occur because estimates of topology and branch lengths below the family level are less accurate than that above the family level. This is likely, both since finer relationships are often more difficult to resolve, and because we were forced to use an interpolation procedure to estimate node ages.

Taxonomy often represents poly- or paraphyletic groupings of taxa, and also fails to account for taxon age, while a reliable phylogeny minimizes these problems; thus, phylogeny should be more powerful in detecting factors correlated with relationship. Nonetheless, it is important to realize that phylogenies are hypotheses about evolutionary history, and should be treated accordingly when incorporated into comparative analyses (Webb et al. 2002). As well, fully resolved phylogenies are still not available for most plant communities, forcing some degree of reliance on taxonomic information: in our case, we still used taxonomy to inform our choice of node ages to include as predictors. Enemy Release and Darwin's Naturalization Hypothesis.

The Enemy Release Hypothesis states that escape from enemies may contribute to the success of 289 exotic species (Keane and Crawley 2002; Torchin and Mitchell 2004; Liu and Stiling 2006). Tests of this hypothesis have produced variable results: exotic plants often do experience reduced levels of damage in new areas but there are numerous exceptions to this rule (Liu \& Stiling 2006). Our results suggest one source of this variation: escape from enemies may depend on the phylogenetic relationship between an invader and members of the invaded community. An exotic plant closely related to natives 294 in the invaded community thus may experience more damage than a phylogenetic outlier. The effects 
we found were modest, and even substantial damage does not necessarily translate to reduced invasiveness or demographic performance (Maron and Vilá 2001; Liu et al. 2007; Dawson et al. 2009); nonetheless, in at least some cases, this biotic resistance might reduce the abundance or spread of an exotic.

If natural enemies are more likely to attack exotics with close native relatives, this could provide a mechanism for Darwin's Naturalization Hypothesis. Although we did not have the data to explicitly test Darwin's Naturalization Hypothesis, evidence in the literature is mixed (Rejmanek 1996; Daehler 2001; Duncan and Williams 2002; Diez et al. 2008); however, this variation may partly reflect the influence of opposing ecological forces operating at different spatial scales (Proches et al. 2008). At regional scales, exotics and close native relatives may positively co-occur because of a requirement for similar physical environments, as Darwin predicted; at local scales, negative biotic interactions such as competition and herbivory may produce negative co-occurrence, as Darwin actually reported (Proches et al. 2008). Diez et al. (2008) found exactly this pattern: at regional scale, the abundance of exotic plants near Auckland, New Zealand was positively correlated with the abundance of native congeners, while at a local (within-habitat) scale this pattern was reversed. Thus, community-scale studies (such as ours) may be required to elucidate the contribution of biotic factors to the patterns discussed by

\section{Darwin.}

Links with community phylogenetics

Darwin's Naturalization Hypothesis represents a precursor to community phylogenetics: the recent theory that communities are in part structured by patterns of evolutionarily conserved traits among component taxa (Webb et al. 2002). Many such studies assume that competition and environmental filtering are the dominant forces structuring communities (e.g., Webb 2000; CavenderBares et al. 2004; Cavender-Bares et al. 2006; Webb et al. 2006; Swenson et al. 2007). For example, where close relatives do not co-occur (i.e., a community is "phylogenetically overdispersed"), the mechanism is assumed to involve limiting similarity resulting in competitive exclusion. However, 
experimental evidence suggests that strong competition among close relatives may not in fact be a

321 leading determinant of community structure (Cahill et al. 2008). Instead, a negative association among 322 relatives could be explained by apparent competition (Holt 1977; Holt and Lawton 1994): the 323 suppression of one species by the enemies of another. Where natural enemies are shared among close 324 relatives, this also could result in phylogenetic overdispersion; our experimental results suggest this 325 may be a plausible alternative. Thus, a century and a half after it was originally proposed, Darwin's 326 Naturalization Hypothesis may lead to a better understanding of the role that phylogeny plays in 327 structuring natural communities, and the mechanisms involved in the success or failure of exotic 328 species.

\section{Acknowledgements}

331 This research was supported by NSERC Research and Equipment Grants (PMK), an NSERC PGS-D 332 (SBH), and the Koffler Scientific Reserve at Jokers Hill. Thanks to Kateryna Kostyukova for her 333 continuous help, to Nathalie Taraban-Lagois, Gilbert Tang, James McKay, and Andrew MacDonald for 334 their support, discussions, and field assistance, and to two anonymous reviewers for valuable 335 suggestions on an earlier version of this manuscript. This is a publication of the Koffler Scientific 336 Reserve. All of the experiments conducted in this study comply with the current laws of Canada. 
References

339 Agrawal AA \& Kotanen PM (2003) Herbivores and the success of exotic plants: a phylogenetically $340 \quad$ controlled experiment. Ecol Lett 6: 712-715

341 Agrawal AA, Kotanen PM, Mitchell CE, Power AG, Godsoe W \& Klironomos J (2005) Enemy

342 release? An experiment with congeneric plant pairs and diverse above- and belowground

$343 \quad$ enemies. Ecology 86: 2979-2989

344 Bailey CD, Koch MA, Mayer M, Mummenhoff K, O'Kane Jr SL, Warwick SI, Windham MD \& Al345 Shehbaz IA (2006) Toward a global phylogeny of the Brassicaceae. Mol Biol Evol 23: 21422160

Burnham KD \& Anderson DA (2002) Model Selection and Multi-Model Inference, 2 edn. Springer,

Cahill JF, Kembel SW, Lamb EG \& Keddy PA (2008) Does phylogenetic relatedness influence the strength of competition among vascular plants? Plant Ecol Evol Syst 10: 41-50

Cappuccino N \& Carpenter D (2005) Invasive exotic plants suffer less herbivory than non-invasive exotic plants. Biol Lett 1: 435-438

Cavender-Bares J, Ackerly DD, Baum DA \& Bazzaz FA (2004) Phylogenetic overdispersion in Floridian oak communities. Am Nat 163: 823-843

Cavender-Bares J, Keen A \& Miles B (2006) Phylogenetic structure of Floridian plant communities depends on taxonomic and spatial scale. Ecology 87: S109-S122

Colautti RI, Ricciardi A, Grigorovich IA \& MacIsaac HJ (2004) Is invasion success explained by the enemy release hypothesis? Ecol Lett 7: 721-733

Crall AW, Meyerson LA, Stohlgren TJ, Jarnevich CS, Newman GJ \& Graham J (2006) Show me the numbers: what data currently exist for non-native species in the USA? Front Ecol Environ 4: 414-418 
363 Darwin C (1859) On the origin of species by means of natural selection. Murray, London, UK

364 Dawson W, Burslem DFRP \& Hulme PE (2009) Herbivory is related to taxonomic isolation, but not to 365 invasiveness of tropical alien plants. Diversity and Distributions 15: 141-147.

366 Dewalt SJ, Denslow JS \& Ickes K (2004) Natural-enemy release facilitates habitat expansion of the 367 invasive tropical shrub Clidemia hirta. Ecology 85: 471-483

368 Diez JM, Sullivan JJ, Hulme PE, Edwards G \& Duncan RP (2008) Darwin's naturalization conundrum: 369 dissecting taxonomic patterns of species invasions. Ecol Lett 11: 674-681

370 Downie SR, Katz-Downie DS \& Watson MF (2000) A phylogeny of the flowering plant family 371 Apiaceae based on chloroplast DNA rpl16 and rpoCl intron sequences: towards a suprageneric 372 classification of subfamily Apioideae. Am J Bot 87: 273-292

373 Duncan RP \& Williams PA (2002) Ecology - Darwin's naturalization hypothesis challenged. Nature $374 \quad 417: 608-609$

375 Freudenstein JV, van den Berg C, Goldman DH, Kores PJ, Molvray M \& Chase MW (2004) An 376 expanded plastid DNA phylogeny of Orchidaceae and analysis of jackknife branch support strategy. Am J Bot 91: 149-157

Funk VA, Bayer RJ, Kelley S, Chan R, Watson L, Gemeinholzer B, Schilling E, Panero JL, Baldwin BG, Garcia-Jacas N, Susanna A \& Jansen RK (2005) Everywhere but Antarctica: using a supertree to understand the diversity and distribution of the Compositae. Biol Skr 55: 343-374

Gilbert GS \& Webb CO (2007) Phylogenetic signal in plant pathogen-host range. P Natl Acad Sci USA 104: 4979-4983

Hillis DM (1987) Molecular versus morphological approaches to systematics. Annu Rev Ecol Syst 18: 
Holt RD (1977) Predation, apparent competition, and structure of prey communities. Theor Popul Biol 12: $197-229$

Holt RD \& Lawton JH (1994) The ecological consequences of shared natural enemies. Annu Rev Ecol Syst, 25: 495-520

Keane RM \& Crawley MJ (2002) Exotic plant invasions and the enemy release hypothesis. Trends Ecol Evol 17: 164-170

Lambdon PW \& Hulme PE (2006) How strongly do interactions with closely-related native species 395 influence plant invasions? Darwin's naturalization hypothesis assessed on Mediterranean islands. J Biogeogr 33: 1116-1125

Långström E \& Chase MW (2002) Tribes of Boraginoideae (Boraginaceae) and placement of Antiphytum, Echiochilon, Ogastemma, and Sericostoma: a phylogenetic analysis based on atpB plastid DNA sequence data. Plant Syst Evol 234: 137-153

Lewinsohn TM, Novotny V \& Basset Y (2005) Insects on plants: diversity of herbivore assemblages revisited. Annu Rev Ecol Syst 36: 597-620

Liu H \& Stiling P (2006) Testing the enemy release hypothesis: a review and meta-analysis. Biol Inv 8:

Liu H, Stiling P \& Pemberton RW (2007) Does enemy release matter for invasive plants? evidence from a comparison of insect herbivore damage among invasive, non-invasive and native congeners. Biol Inv 9: 773-781

Mack RN, Simberloff D, Lonsdale WM, Evans H, Clout M \& Bazzaz FA (2000) Biotic invasions: Causes, epidemiology, global consequences, and control. Ecol Appl 10: 689-710

Maron JL \& Vila M (2001) When do herbivores affect plant invasion? Evidence for the natural enemies and biotic resistance hypotheses. Oikos 95: 361-373

411 Mitchell CE, Agrawal AA, Bever JD, Gilbert GS, Hufbauer RA, Klironomos JN, Maron JL, Morris 412 WF, Parker IM, Power AG, Seabloom EW, Torchin ME \& Vazquez DP (2006) Biotic 
414 Mitchell CE \& Power AG (2003) Release of invasive plants from fungal and viral pathogens. Nature $415 \quad 421: 625-627$

416 Morton JK \& Venn JM (1990) A checklist of the flora of Ontario: vascular plants. University of 417 Waterloo Biology Series Waterloo, Ontario, Canada

418 Natali A, Manen J-F \& Ehrendorfer F (1995) Phylogeny of the Rubiaceae-Rubioideae, in particular the 419 tribe Rubieae: evidence from a non-coding chloroplast DNA sequence. Ann Missouri Bot Garden 420 82: 428-439

Novotny V \& Basset Y (2005) Host specificity of insect herbivores in tropical forests. P Roy Soc BBiol Sci 272: 1083-1090

Novotny V, Basset Y, Miller SE, Weiblen GD, Bremer B, Cizek L \& Drozd P (2002) Low host specificity of herbivorous insects in a tropical forest. Nature 416: 841-844

Odegaard F, Diserud OH \& Ostbye K (2005) The importance of plant relatedness for host utilization among phytophagous insects. Ecol Lett 8: 612-617

Olmstead RA, dePamphilis CW, Wolfe AD, Young ND, Ellisons WJ \& Reeves PA (2001)

Oxelman B, Lidén M \& Berglund D (1996) Chloroplast rps16 intron phylogeny of the tribe Sileneae (Caryophyllaceae). Plant Syst Evol 206: 393-410

Parker JD, Burkepile DE \& Hay ME (2006) Opposing effects of native and exotic herbivores on plant 432 invasions. Science 311: 1459-1461

Parker JD \& Hay ME (2005) Biotic resistance to plant invasions? Native herbivores prefer non-native plants. Ecol Lett 8: 959-967

Paton AJ, Springate D, Suddee S, Otieno D, Grayer RJ, Harley MM, Willis F, Simmonds MSJ, Powell MP \& Savolainen V (2004) Phylogeny and evolution of basils and allies (Ocimeae, Labiatae) based on three plastid DNA regions. Mol Phylogenet Evol 31: 277-299 
438 Pimentel D, Lach L, Zuniga R \& Morrison D (2000) Environmental and economic costs of

439 nonindigenous species in the United States. Bioscience 50: 53-65

440 Potter D, Erickson T, Evans RC, Oh S, Smedmark JEE, Morgan DR, Kerr M, Robertson KR, Arsenault

441 M, Dickinson TA \& Campbell CS (2007) Phylogeny and classification of Rosaceae. Plant Syst

$442 \quad$ Evol 266: 5-43

443 Proches S, Wilson JRU, Richardson DM \& Rejmanek M (2008) Searching for phylogenetic pattern in 444 biological invasions. Global Ecol Biogeogr 17: 5-10

445 Rejmanek M (1996) A theory of seed plant invasiveness: the first sketch. Biol Conserv, 78: 171-181

446 R Development Core Team (2006) R: A language and environment for statistical computing. R

447 Foundation for Statistical Computing, Vienna, Austria ISBN 3-900051-07-0, URL http://wwwR-

$448 \quad$ projectorg

449 Ro K-E, Keener CS \& McPheron BA (1997) Molecular phylogenetic study of the Ranunculaceae:

450 utility of the nuclear 26S ribosomal DNA in inferring intrafamilial relationships. Mol Phylogenet

$451 \quad$ Evol 8: 117-127

452 Ronsted N, Chase MW, Albach DC \& Bello MA (2002) Phylogenetic relationships within Plantago

453 (Plantaginaceae): evidence from nuclear ribosomal ITS and plastid trnL-F sequence data. Bot J

$454 \quad$ Linn Soc 139: 323-338

455 SAS Institute Inc (2002) JMP version 5.0 In SAS Institute. Cary, North Carolina, USA

456 Smedmark JEE \& Erickson T (2002) Phylogenetic relationships of Geum (Rosaceae) and relatives

457 inferred from the nrITS and trnL-trnF regions. Syst Bot 27: 303-317

458 Smissen RD, Clement JC, Garnock-Jones PJ \& Chambers GK (2002) Subfamilial relationships within

459 Caryophyllaceae as inferred from 5' ndhF sequences. Am J Bot 89: 1336-1341

460 Strauss SY, Webb CO, Salamin, N (2006) Exotic taxa less related to native species are more invasive.

$461 \quad$ PNAS 15: 5841-5845

462 Strong DR, Lawton JH \& Southwood R (1984) Insects on plants. Harvard University Press, 
464 Swenson NG, Enquist BJ, Thompson J \& Zimmerman JK (2007) The influence of spatial and size 465 scale on phylogenetic relatedness in tropical forest communities. Ecology 88: 1770-1780 466 Torchin ME \& Mitchell CE (2004) Parasites, pathogens, and invasions by plants and animals. Front $467 \quad$ Ecol Environ 2: 183-190

468 Wagstaff SJ, Hickerson L, Spangler R, Reeves PA \& Olmsted RA (1998) Phylogeny in Labiatae s 1 469 inferred from cpDNA sequences. Plant Syst Evol 209: 265-274

470 Webb CO (2000) Exploring the phylogenetic structure of ecological communities: an example for rain $471 \quad$ forest trees. Am Nat 156: $145-155$

472 Webb CO, Ackerly DD, McPeek MA \& Donoghue MJ (2002) Phylogenies and community ecology. $473 \quad$ Annu Rev Ecol Syst 33: 475-505

474 Webb CO \& Donoghue MJ (2005) Phylomatic: tree assembly for applied phylogenetics. Mol Ecol $475 \quad$ Notes 5: 181-183

476 Webb CO, Gilbert GS \& Donoghue MJ (2006) Phylodiversity-dependent seedling mortality, size 477 structure, and disease in a Bornean rain forest. Ecology 87: S123-S131

478 Weiblen GD, Webb CO, Novotny V, Basset Y \& Miller SE (2006) Phylogenetic dispersion of host use 479 in a tropical insect herbivore community. Ecology 87: S62-S75

480 Wikstrom N, Savolainen V \& Chase MW (2001) Evolution of the angiosperms: calibrating the family 481 tree. P Roy Soc Lond B Bio 268: 2211-2220

482 
483 Table 1. List of exotic plants sampled in common gardens and natural populations. Bolded families 484 have native members at the study site (the Koffler Scientific Reserve). Nomenclature follows Morton 485 and Venn (1990) 486

\begin{tabular}{|c|c|c|c|}
\hline Family & Species & Common Garden & Natural Populations \\
\hline Amaranthaceae & Amaranthus retroflexus L. & & $\mathrm{X}$ \\
\hline Apiaceae & Daucus carota L. & $\mathrm{X}$ & $\mathrm{X}$ \\
\hline Asclepiadaceae & Cynanchum rossicum (Kleopov) Borh. & & $\mathrm{X}$ \\
\hline Asteraceae & Arctium minus (Hill) Bernh. & $\mathrm{X}$ & $\mathrm{X}$ \\
\hline Asteraceae & Centaurea jaceae L. & & $\mathrm{X}$ \\
\hline Asteraceae & Cirsium arvense (L.) Scop. & $\mathrm{X}$ & $\mathrm{X}$ \\
\hline Asteraceae & Cirsium vulgare (Savi) Tenore & & $\mathrm{X}$ \\
\hline Asteraceae & Cichorium intybus L. & $\mathrm{X}$ & $\mathrm{X}$ \\
\hline Asteraceae & Chrysanthemum leucanthemum L. & $\mathrm{X}$ & $\mathrm{X}$ \\
\hline Asteraceae & Hieracium aurantiacum L. & $\mathrm{X}$ & \\
\hline Asteraceae & Hieracium caespitosum Dumort. & & $\mathrm{X}$ \\
\hline Asteraceae & Inula helenium L. & & $\mathrm{X}$ \\
\hline Asteraceae & Sonchus arvensis L. & & $\mathrm{X}$ \\
\hline Asteraceae & Tragopogon dubius Scop. & & $X$ \\
\hline Asteraceae & Tragopogon pratensis L. & $X$ & \\
\hline Asteraceae & Tussilago farfara L. & & $\mathrm{X}$ \\
\hline Boraginaceae & Cynoglossum officinalis L. & & $X$ \\
\hline Boraginaceae & Echium vulgaris L. & $\mathrm{X}$ & $X$ \\
\hline Brassicaceae & Alliaria petiolata (M. Bieb.) Cav. \& Gr. & & $\mathrm{X}$ \\
\hline
\end{tabular}


Brassicaceae Capsella bursa-pastoris (L.) Medikus $\quad \mathrm{X}$

Brassicaceae Erysimum cheiranthoides L. $\quad \mathrm{X}$

Brassicaceae Hesperis matronalis L. X X

Brassicaceae Lepidium campestre (L.) R.Br. $\quad$ X

Brassicaceae Sinapis arvensis L. X X

Brassicaceae Thlaspi arvense L. X

Campanulaceae Campanula rapunculoides L. X X

Caryophyllaceae Dianthus armeria L. X

Caryophyllaceae Saponaria officinalis L. X X

Caryophyllaceae Silene latifolia Poiret $\quad$ X $\quad$ X

Caryophyllaceae Silene noctiflora L. X X

Caryophyllaceae Silene vulgaris (Moench) Garcke $\quad$ X $\quad$ X

Chenopodiaceae Chenopodium album L. $\quad$ X

$\begin{array}{llll}\text { Clusiaceae } & \text { Hypericum perforatum L. } & \text { X }\end{array}$

Convolvulaceae Convolvulus arvensis L. $\quad \mathrm{X}$

Dipsacaceae Dipsacus sylvestris Hudson X

Euphorbiaceae Euphorbia cyparissias L. $\quad$ X $\quad$ X

Fabaceae Lotus corniculatus L. $\quad$ X

Fabaceae $\quad$ Medicago lupulina L. X

Fabaceae $\quad$ Medicago sativa L. X X

$\begin{array}{llll}\text { Fabaceae } & \text { Melilotus alba Medikus } & \text { X }\end{array}$

Fabaceae Melilotus officinalis (L.) Pallas $\quad$ X

$\begin{array}{llll}\text { Fabaceae } & \text { Trifolium pratense L. } & \text { X }\end{array}$

Fabaceae Vicia cracca L. X X 
Fabaceae Vicia tetrasperma (L.) Moench X

Lamiaceae Glechoma hederaceae L. X X

Lamiaceae Leonurus cardiaca L. X X

Lamiaceae $\quad$ Mentha X piperita L. X

Lamiaceae Nepeta cataria L. $\quad$ X

Lythraceae $\quad$ Lythrum salicaria L. X

Orchidaceae Epipactis helleborine (L.) Crantz X

Papaveraceae Chelidonium majus L. $\quad$ X

Plantaginaceae Plantago lanceolata L. $\quad \mathrm{X}$

Plantaginaceae Plantago major L. $\quad$ X

Polygonaceae Rumex crispus L. X X

Ranunculaceae Ranunculus acris L. $\quad$ X

$\begin{array}{llll}\text { Rubiaceae } & \text { Galium verum L. } & \text { X }\end{array}$

$\begin{array}{llll}\text { Rosaceae } & \text { Potentilla recta L. } & \text { X }\end{array}$

Scrophulariaceae Linaria vulgaris Hill $\quad \mathrm{X} \quad \mathrm{X}$

Scrophulariaceae Verbascum thapsus L. $\quad$ X

$\begin{array}{llll}\text { Solanaceae } & \text { Solanum dulcamara L. } & \text { X }\end{array}$

\begin{tabular}{lll}
\hline Total species & 32 & 52
\end{tabular}


491 Table 2. Regression and AIC results for herbivory (proportion of leaves damaged and leaf area

492 damaged) vs. phylogenetic distance to native species occurring at KSR. Damage variables were probit 493 transformed and phylogenetic distance measures were natural logarithm transformed before analysis.

494 Headers represent degrees of freedom (df) used to test the significance of the regression slope (F, p), 495 and Akaike's information criteria (AIC), Akaike weights (w), and variance explained $\left(\mathrm{r}^{2}\right)$ to determine 496 the best phylogenetic distance model

497

Proportion of Leaves Damaged

Leaf Area Damaged

\begin{tabular}{|c|c|c|c|c|c|c|c|c|c|c|c|c|}
\hline Data & $\begin{array}{l}\text { Phylogenetic } \\
\text { distance }\end{array}$ & $\mathrm{df}$ & $\mathrm{F}$ & $\mathrm{p}$ & AIC & $\mathrm{w}$ & $r^{2}$ & $\mathrm{~F}$ & $\mathrm{p}$ & AIC & $\mathrm{w}$ & $r^{2}$ \\
\hline Common & $\begin{array}{l}\text { All native } \\
\text { taxa }\end{array}$ & 1,30 & 0.030 & 0.865 & 74.700 & 0.30 & 0.00 & 0.041 & 0.840 & 48.706 & 0.26 & 0.00 \\
\hline $\begin{array}{l}\text { Garden } \\
\text { (June) }\end{array}$ & $\begin{array}{l}\text { Native family } \\
\text { taxa }\end{array}$ & 1,30 & 0.544 & 0.467 & 74.156 & 0.40 & 0.00 & 1.302 & 0.263 & 47.391 & 0.49 & 0.01 \\
\hline & Closest native & 1,30 & 0.000 & 1.000 & 74.731 & 0.30 & 0.00 & 0.004 & 0.953 & 48.746 & 0.25 & 0.00 \\
\hline
\end{tabular}

All native

Common taxa

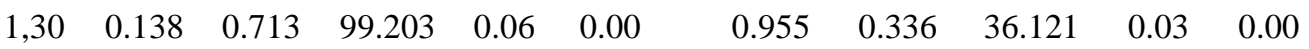

Garden Native family

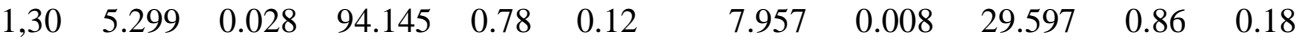

(August) taxa

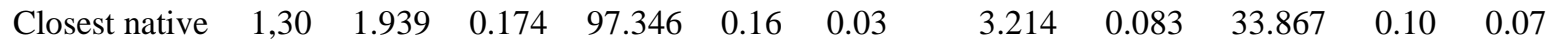

All native

$\begin{array}{lllllllllll}1,50 & 2.232 & 0.142 & 22.715 & 0.59 & 0.00 & 0.003 & 0.956 & 81.079 & 0.31 & 0.00\end{array}$

taxa

Native family

$\begin{array}{lllllllllll}1,50 & 0.003 & 0.958 & 24.983 & 0.19 & 0.00 & 0.000 & 0.997 & 81.082 & 0.31 & 0.00\end{array}$

taxa

$\begin{array}{llllllllllll}\text { Closest native } & 1,50 & 0.341 & 0.562 & 24.633 & 0.22 & 0.00 & 0.440 & 0.510 & 80.626 & 0.39 & 0.00\end{array}$ 
Figure legends

Fig. 1 Proportion of leaves damaged in the common garden experiment versus phylogenetic distance to a) all native species, b) native family members, c) closest native relative, and proportion of leaf area damaged against phylogenetic distance to d) all native species, e) native family members, f) closest native relative. All damage measures were made during August 2005, and phylogenetic distances are based on tip-to-tip distances between exotic and native species present at KSR. Points represent means for each species. Intact lines indicate regressions significant at $\mathrm{p}<0.05$, the broken line indicates significance at $\mathrm{p}<0.1$

Fig. 2 Proportion of leaves damaged in naturally occurring populations at KSR versus phylogenetic distance to a) all native species, b) native family members, c) closest native relative, and proportion of leaf area damaged against phylogenetic distance to d) all native species, e) native family members, f) closest native relative. All damage measures were made during July and August 2005, and phylogenetic distances are based on tip-to-tip distances between exotic and native species present at KSR. Points represent means for each species included in the survey. No regressions were significant $(p>0.1)$ 
Figure 1
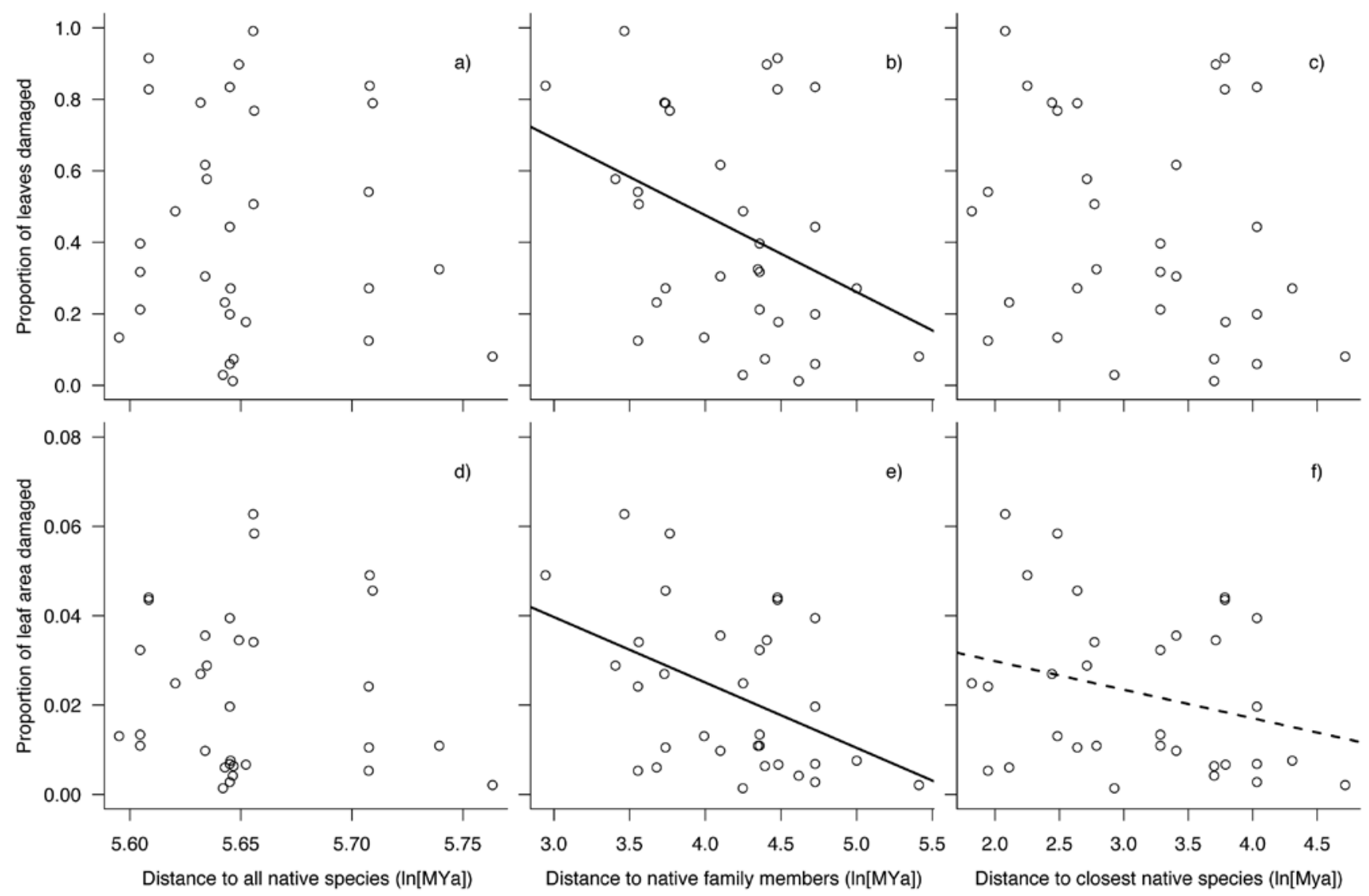
Figure 2
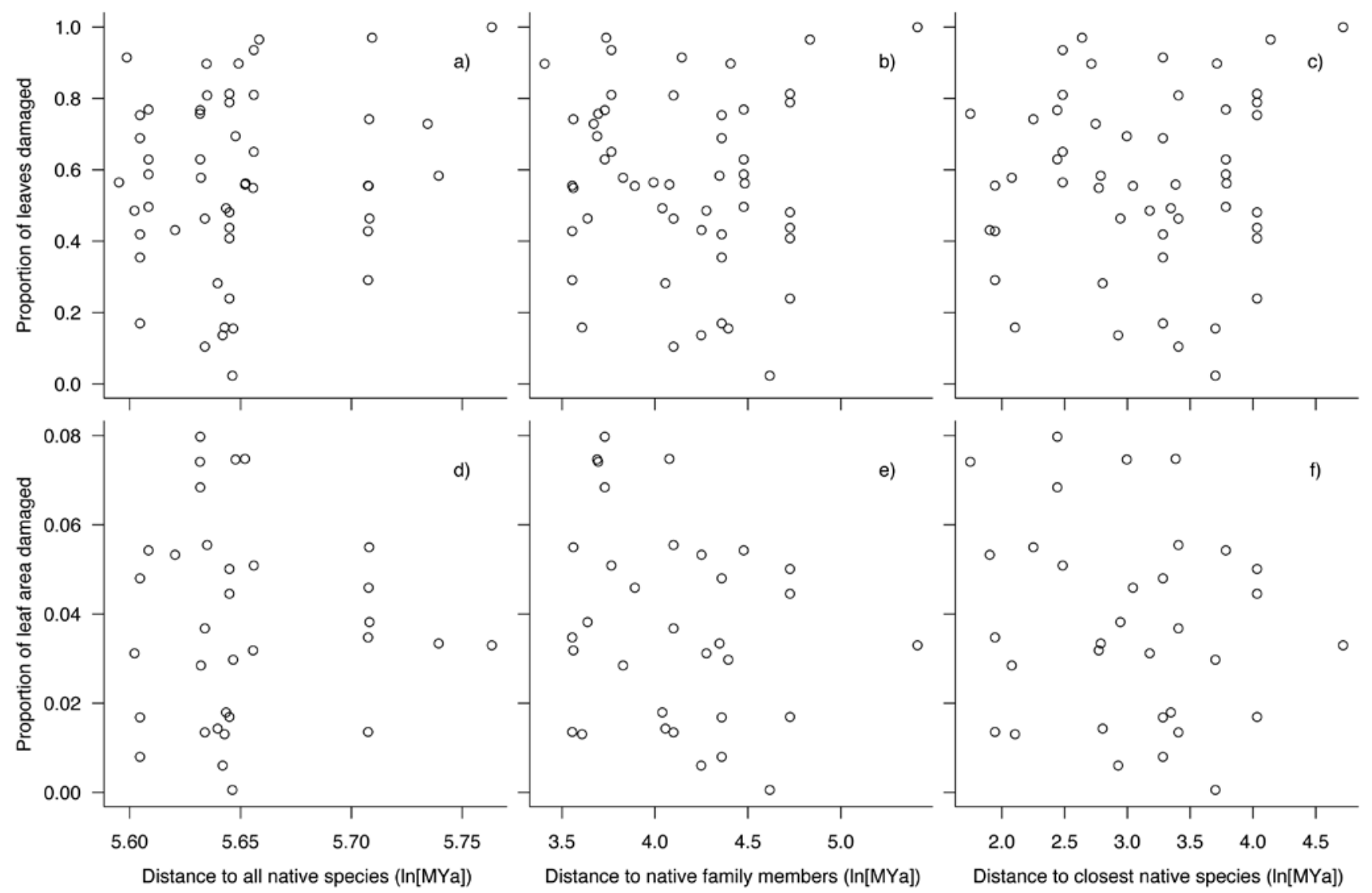